\title{
Do we need to check for asthma in subjects with allergic rhinitis?
}

\author{
A. Di Franco, P.L. Paggiaro
}

Monaldi Arch Chest Dis 2005; 63: 2, 72-73.

Cardio-Thoracic Department, University of Pisa, Italy.

Correspondence: Prof. Pierluigi Paggiaro, Fisiopatologia Respiratoria, Dipartimento Cardio-Toracico, Ospedale Cisanello, Via Paradisa 2; 56100 Pisa, Italy; e-mail: ppaggiaro@qubisoft.it

In the last 10 years much interest has been directed towards the relationship between upper and lower airways, in particular between rhinitis and asthma. Several clinical and epidemiological studies have shown a strong association between rhinitis and asthma. Rhinitis has been demonstrated to be a major risk for asthma occurrence [1], with rhinitis often preceding the onset of asthma both in atopic and non atopic subjects, and non-specific bronchial hyperresponsiveness can be frequently documented in allergic rhinitic subjects without asthma symptoms [2]. Conversely, upper airway infection can be frequently a trigger for asthma exacerbations [3], and rhinosinusitis can be responsible for insufficient control of asthma [4]. These facts suggest a common pathogenetic mechanism underlying these two diseases.

Bronchial hyper-responsiveness is a common trait of asthma; however it can be observed consistently in subjects with rhinitis without asthma symptoms [2], although it is not clear whether these subjects are poor perceivers of few episodes of mild bronchoconstriction. Bronchoconstriction not associated with asthma symptoms has been reported in subjects with seasonal allergic rhinitis observed during pollen season [5], and bronchial responsiveness to methacholine, histamine, carbachol or exercise often increases during season in these subjects [6-8]. Subjects with perennial allergic rhinitis have often a greater bronchial hyper-responsiveness than subjects with seasonal allergic rhinitis $[9,10]$. A recent epidemiological study has demonstrated that bronchial hyper-responsiveness is increased in subjects with both perennial and seasonal allergic rhinitis than in subjects with seasonal rhinitis or in normal subjects [11]. Almost $50 \%$ of subjects with NARES (Non Allergic Rhinitis with Eosinophilia) but without asthma symptoms show bronchial hyper-responsiveness associated with sputum eosinophilia; these findings however are not associated with increased markers of nasal inflammation [12]. Hyperreactive subjects with rhinitis can be at higher risk for asthma onset, as suggested by a recent longitudinal epidemiological study [13].

In this issue of the journal, Cirillo et al. reported a study showing that subjects with allergic rhinitis but without asthma symptoms showed a significant proportion of pulmonary function abnormalities and bronchial hyper-responsiveness to metha- choline, and that these abnormalities were more relevant during the period of exposure to the specific allergens (14). This data is in accordance with other reports from the literature, suggesting that a subclinical asthma-like functional abnormalities can be detected in a considerable percentage of subjects with apparently "simple" allergic rhinitis.

It has been widely demonstrated that markers of inflammation can be detected in the lower airways of subjects with rhinitis. Allergic rhinitic subjects with bronchial hyper-responsiveness show increased amounts of eosinophils, basophils and mastcells in the lower airways also when they are not naturally exposed to the specific allergen $[15,16]$. Furthermore, an inflammatory response similar to that observed in asthma has been documented in the lower airways of non-asthmatic subjects with allergic rhinitis who underwent to a nasal allergen challenge followed, 24 hours later, by nasal and endobronchial biopsies [17]. The same authors have demonstrated also that segmental allergen challenge in subjects with allergic rhinitis induced a mucosal eosinophilic inflammation associated with an increase in blood eosinophils [18]. Using induced sputum technique, Polosa et al. have demonstrated that allergic rhinitic subjects without asthma symptoms showed sputum eosinophilia during the periods of allergen exposure [19]. Finally, some studies have evaluated the lower airway inflammatory response after specific allergen challenge in asthmatic and rhinitic subjects. Using bronchial biopsy specimens and bronchoalveolar lavage, these authors showed that no significant qualitative difference was observed between rhinitic and asthmatic subjects as regards the pattern of inflammatory response in the lower airways [20]. This data suggests that there is "continuum" between allergic rhinitis and allergic asthma, and that these two diseases are strongly associated and related to the same allergic mechanisms.

This data has relevant implications both for prevention and for treatment. If asthma often follows the onset of allergic rhinitis, subjects with allergic rhinitis should be intensively monitored also for bronchial hyper-responsiveness, PEF variability and the presence of markers of lower airways inflammation, in order to detect initial features of asthma. However, it is not known if this prompt recognition of asthma features can have a positive 
influence on the natural history of asthma in these subjects. As regards treatment, it could be speculated that treatment addressed to control rhinitis could modify bronchial hyperresponsiveness and delay the onset of asthma. In 1987 it has been reported that intranasal sodium cromoglycate and beclomethasone dipropionate were able in reducing not only seasonal rhinitic symptoms but also seasonal asthma symptoms [21]. Intranasal corticosteroids caused a greater improvement in bronchial hyper-responsiveness than intrabronchial corticosteroids [22]. Conversely, inhaled corticosteroids are able to improve also nasal symptoms and markers of nasal inflammation in subjects with asthma and rhinitis [23]. Recently, orally administered leukotriene receptor antagonists, like montelukast of zafirlukast, have been demonstrated to be effective both on rhinitic and asthmatic components of these subjects, with high compliance to the treatment [24].

However this strong association between asthma and rhinitis is mainly limited to allergic subjects. Asthma is an heterogeneous disease, and many subjects do not show allergic features. In these subjects the relationship with nasal symptoms and nasal inflammation is still present, but at a lower degree. Furthermore, the relationship between upper and lower airways is not limited to the presence of a common pathophysiologic mechanism mainly related to a Th2-type inflammation, but also to other factors (like reflex mechanisms, mechanical factors, etc).

In summary, papers like that of Cirillo et al [14] underline the need to study rhinitic subjects accurately and frequently, in order to check for early asthma symptoms and functional abnormalities. Considering that early diagnosis and early treatment in asthma has been associated with a favourable course of the disease [25], this attention to asthma features in rhinitic subjects could be useful for a better management of asthma.

\section{References}

1. Leynaert B, Bousquet J, Neukirch C, Liard R, Neukirk F. Perennial rhinitis: an indipendent risk factor for asthma. J Allergy Clin Immunol 1999; 104: 301-304.

2. Townley RG, Ryo UY, Kolotkin BM, Kang B. Bronchial sensitivity to methacholine in current and former asthmatic and allergic rhinitis patients and control subjects. J Allergy Clin Immunol 1975; 56: 429-42.

3. Van Cauwenberge PB, Vermeiren JS, van Kempen MJ. Viral rhinitis and asthma. Curr Opin Allergy Clin Immunol 2001; 1: 21-5.

4. Fox RW, Lockey RF. The impact of rhinosinusitis on asthma. Curr Allergy Asthma Rep 2003; 3: 513-518.

5. Gerblich AA, Schwartz HJ, Chester EH. Seasonal variation of airway function in allergic rhinitis. J Allergy Clin Immunol 1986; 77: 676-81.

6. Madonini E, Briatico-Vangosa G, Pappacoda A, Maccagni G, Cardani A, Saporiti F. Seasonal increase of bronchial reactivity in allergic rhinitis. J Allergy Clin Immunol 1987; 79: 358-63.

7. Karjalainen J, Lindqvist A, Laitinen LA. Seasonal variability of exercise-induced asthma especially outdoors. Effect of birch pollen allergy. Clin Exp Allergy 1989; 19: 273-8.
8. Prieto L, Lopez M, Berto JM, Peris A. Modification of concentration-response curves to inhaled methacholine after the pollen season in subjects with pollen induced rhinitis. Thorax 1994; 49: 711-3.

9. Verdiani P, Di Carlo S, Baronti A. Different prevalence and degree of nonspecific bronchial hyperreactivity between seasonal and perennial rhinitis. J Allergy Clin Immunol 1990; 86: 576-82.

10. Prieto JL, Gutierrez V, Berto JM, Camps B. Sensitivity and maximal response to methacholine in perennial and seasonal allergic rhinitis. Clin Exp Allergy 1996; 26: 61-7.

11. Leynaert B, Bousquet J, Henry C, Liard R, Neukirch F. Is bronchial hyperresponsiveness more frequent in women than in men? A population-based study. Am $J$ Respir Crit Care Med 1997; 156: 1413-20.

12. Leone C, Teodoro C, Pelucchi A, et al. Bronchial responsiveness and airway inflammation in patients with nonallergic rhinitis with eosinophilia syndrome. $J$ Allergy Clin Immunol 1997; 100: 775-80.

13. Guerra S, Sherril DL, Baldacci S, et al. Rhinitis is an independent risk factor for developing cough apart from common colds among adults. Allergy 2005; 60: 343-349.

14. Cirillo I, Vizzaccaro A, Tosca MA, et al. Bronchial hyprerreactivity and spirometric impairment in patients with allergic rhinitis. Monaldi Arch Chest Dis 2005; 63: 79-93.

15. Foresi A, Leone C, Pelucchi A et al. Eosinophils, mast cells, and basophils in induced sputumfrom patients with seasonal allergic rhinitis and perennial asthma: relationship to methacholine responsiveness. J Allergy Clin Immunol 1997; 100: 58-64

16. Chanez P, Vignola AM, Vic P, Guddo F, Bonsignore G, Godard P. Comparison between nasal and bronchial inflammation in asthmatic and control subjects. Am $J$ Respir Crit Care Med 1999; 159: 588-95

17. Braunstahl G, Overbeek SE, Kleinjan A, Prins JB, Hoogsten HC, Fokkens WJ. Nasal allergen provocation in expression and tissue eosinophilia in upper and lower airways. J Allergy Clin Immunol 2001; 107: 469-476.

18. Braunstahl G, Kleinjan A, Overbeek SE, Prins JB, Hoogsten HC, Fokkens WJ. Segmental bronchial provocation binduces nasal inflammation in allergic rhinitis patients. Am J Respir Crit Care Med 2000; 161 : 2051-2057.

19. Polosa R, Ciamarra I, Mangano G, et al. Bronchial hyperresponsiveness and airway inflammation markers in nonasthmatics with allergic rhinitis. Eur Resp J 2000; 15: 30-35.

20. Crimi E, Milanese M, Oddera S, et al. Inflammatory and mechanical factors of allergen-induced bronchoconstriction in mild asthma and rhinitis. J Appl Physiol 2001; 91: 1029-1034.

21. Welsh PW, Stricker WE, Chu C-P, et al. Efficacy of beclometasone nasal solution, flunisolide, and cromolyn in relieving symptoms of ragweed allergy. Mayo Clin Proc 1987; 62: 125-34

22. Aubier M, Levy J, Clerici C, Neukirch F, Herman D. Different effects of nasal and bronchial glucocorticosteroid administration on bronchial hyperresponsiveness in patients with allergic rhinitis. Am Rev Respir Dis 1992; 146: 122-6

23. Greiff L, Andersson M, Svensson C, et al. Effects of orally inhaled budesonide budesonide in seasonal allergic rhinitis. Eur Respir J 1998; 11: 1268-74

24. Philip G, Nayak AS, Berger WE, et al. The effect of montelukast on rhinitis symptoms in patients with asthma and seasonal allergic rhinitis. Curr Med Res Opin 2004; 20: 549-558.

25. Pauwels RA, Pedersen S, Busse WW, et al. Early intervention with budesonide in mild persistent asthma: a randomised, double-blind trial. Lancet 2003; 361: 1071-1076. 